\title{
A model of total volume stability for preparing polymorph zirconia ceramics as functional structure materials
}

\author{
Yonggang Hoo, ${ }^{\text {a, } b, *}$ Yusheng Shi ${ }^{\mathrm{a}}$ and Wenzhong $\mathrm{Lu}^{\mathrm{b}}$ \\ ${ }^{a}$ State Key Laboratory of Materials Processing and Die \& Mould Technology, School of Materials Science \\ and Engineering, Huazhong University of Science and Technology, Wuhan 430074, China \\ ${ }^{b}$ School of Optical and Electronic Information, Huazhong University of Science and Technology, Wuhan \\ 430074, China
}

Keywords: effective transition field, volume stability, thermal shock durability, self-restoration

\section{Summary}

In this study, a parameter of volume stability was proposed for the first time to design polymorph zirconia ceramics used for special components. A series of heterogeneous polymorph zirconia ceramics with various amounts of monoclinic (M) phase were fabricated by two-step sintering. Samples with about 27\%, 31\%, and 51\% M phase content were selected to study the properties. The thermal shock durability was found to be associated with thermal expansion behavior and noncritical micro cracks, which both based on M phase initial content. In good agreement with experimental results, the correlation of normalized $\mathrm{K}$ versus $\mathrm{M}$ phase initial content was established. It could provide a repeatable reference to prepare special zirconia components without loss of density.

\section{Introduction}

High temperature structure ceramics have been used in turbine blade, gas turbine spout etc. It is eagerly required to enhance the engine potentiality and develop ceramic devices with higher life and lower maintenance. Much effort had been spent for the development of polymorph zirconia as a high temperature structure ceramic, but it was not as expected owing to the unanticipated transformation after prepared. The expansion or contraction from transformation would be restricted by adjacent grains and the structural stresses would occur accompanied with transformation if the adopted unreasonable preparation. In this case, thermal failure will occur at elevated temperature.

For avoiding the failure, many theories have been proposed and accepted by most researchers. For example, Kingery [1] concluded a stress relaxed mechanism and a strength theory based on single phase. Hasselman [2] determined that "the material properties should be selected so as the crack stability", called the crack theory, which also based on the simple brittle ceramics. Salvini [3] extended Hasselman's work by considering the interaction of cracks and microstructure. WG Li [4] suggested a modified Hasselman`s function by considering the initial temperature of thermal environment and surface heat transfer coefficient to calculate the critical damage temperature of Ultra-High Temperature Ceramics (UHTCs). However, for transformational material, those theories have some limitations on the guide of preparing of polymorph zirconia.

Gogotsi [5,6] considered the brittleness as a design parameter and pointed out that the estimates of mechanical behavior were not reliable enough without considering the transformation. Physically, as for compact polymorph zirconia, the aforementioned factors such as crack size, brittleness, heat exchange conditions or Biot modulus [7], and size of sample could be varied with transformation. Moreover, accompanied with a considerable volume change, whether bring about or relieve inter stresses that depended on whether the structural expansion or shrinkage is free or not [1]. In this paper, for the first time, a volume stability model is proposed to ensure the free structural expansion or shrinkage after the preparation of polymorph zirconia. Samples were sintered to obtain heterogeneous polymorph zirconia with different M phase content. Samples with about 27\%, 31\%, and 51\% M phase were selected to study the properties. The residual strengths were tested to describe the thermal shock performance. The effects of thermal expansion behavior, total volume change, $\mathrm{M}$ phase content and the effective transition region are considered. Based on the experimental results, the correlation of normalized $\mathrm{K}$ and volume change that varied with the $\mathrm{M}$ phase initial content is discussed.

*Author for correspondence (yongganghu@hust.edu.cn).

$\uparrow$ Present address: State Key Laboratory of Materials Processing and Die \& Mould Technology, School of Materials Science and Engineering Huazhong University of Science and Technology, Wuhan 430074, China. 


\section{Mathematical model and Experimental}

\section{Modelling of volume stability}

As shown in figure 1, the requirements of thermal shock failure in ceramics are (1) adequate temperature difference; (2) inner stresses from temperature or structure; (3) intrinsic structure change versus initial state and (4) cracks nucleation or propagation in substrate. The existent theories provide extremely good description on (1), (2) and (4). But for polymorph zirconia ceramics, plenty information had little description on (3) in traditional theories. Keeping the volume stable could give an important way to optimize the thermal performance. If the polymorph zirconia ceramic contains three phases $\mathrm{M}$, $\mathrm{T}$ (tetragonal) and $\mathrm{C}$ (cubic) at normal temperature, there could be volume contraction accompanied with the $\mathrm{M}$ phase entirely changed into T during heating-up. An equation of varied volume state is described as

$$
\begin{aligned}
& \mathrm{K}=\frac{\Delta \mathrm{V}_{\mathrm{M} \rightarrow \mathrm{T}}}{\Delta \mathrm{V}_{\mathrm{M}+\mathrm{T}+\mathrm{T}}^{\mathrm{T}_{\mathrm{T}}}} \\
& \left(\text { where: } \Delta \mathrm{V}_{\mathrm{M}+\mathrm{T}+\mathrm{C}}^{\mathrm{T}_{M} \rightarrow \mathrm{T}}=\sum_{\mathrm{T}<\mathrm{T}_{\mathrm{M} \rightarrow \mathrm{T}}}^{\mathrm{i}=\mathrm{M}, \mathrm{T}, \mathrm{C}} \mathrm{V}_{\mathrm{i}}\right)
\end{aligned}
$$

$\mathrm{T}_{\mathrm{M}-\mathrm{T}}$ is the instantaneous temperature when $\mathrm{M}$ phase entirely transited to $\mathrm{T}$ phase.

$$
\mathrm{K}^{\prime}=\frac{\Delta \mathrm{V}_{\mathrm{T} \rightarrow \mathrm{C}} / \Delta \mathrm{V}_{\mathrm{M}+\mathrm{T}+\mathrm{C}}^{\mathrm{T}_{\mathrm{M} \rightarrow \mathrm{T}}}+\mathrm{K}}{1+\sum_{\mathrm{T}_{\mathrm{M} \rightarrow \mathrm{T}}}^{\mathrm{T}_{\mathrm{T}} \mathrm{C}} \Delta \mathrm{V}_{\mathrm{T}+\mathrm{C}} / \Delta \mathrm{V}_{\mathrm{M}+\mathrm{T}+\mathrm{C}}^{\mathrm{T}_{\mathrm{T}}}}
$$

With the temperature increasing, the thermal expansion continues, then there follows a small shrinkage after $\mathrm{T}$ to $\mathrm{C}$ transformation. The relative volume change can be formulated as (2). The $\Delta \mathrm{V}_{\mathrm{T} \rightarrow \mathrm{C}}$ is much smaller than the $\Delta \mathrm{V}_{\text {thermal }}$ expansion at such high temperature, which could be neglected in Eq. (2). Therefore, the equation (2) can be simplified as

$$
\mathrm{K}^{\prime}=\frac{\mathrm{K}}{{ }_{1+}^{\sum_{\mathrm{T}_{\mathrm{M} \rightarrow \mathrm{T}}}^{\mathrm{T}_{\mathrm{T}}} \Delta \mathrm{V}_{\mathrm{T}+\mathrm{C}}} /{ }_{\Delta \mathrm{V}_{\mathrm{M}+\mathrm{T}+\mathrm{C}}^{\mathrm{T}_{\mathrm{M}} \rightarrow \mathrm{T}}}}
$$

Similarly, the other case, with the temperature increasing to $\mathrm{T}_{\mathrm{C}}$, the volume change state can be simplified as

$$
\mathrm{K}^{\prime \prime}=\frac{\mathrm{K}}{1+\sum_{\mathrm{T}_{\mathrm{M} \rightarrow \mathrm{T}}}^{\mathrm{T}_{\mathrm{T} \rightarrow \mathrm{C}}} \Delta \mathrm{V}_{\mathrm{T}+\mathrm{C}}+\Delta \mathrm{V}_{\mathrm{C}} / \mathrm{V}_{\mathrm{M}+\mathrm{T}+\mathrm{C}}^{\mathrm{T}_{\mathrm{M} \rightarrow \mathrm{T}}}}
$$

where $\Delta \mathrm{V}_{\mathrm{i}}=\mathrm{V}^{0}{ }_{\mathrm{i}} \alpha_{\mathrm{i}} \Delta \mathrm{T}, \mathrm{V}^{0}{ }_{\mathrm{i}}$ is the initial volume fraction of each phase at normal temperature, $\alpha \mathrm{i}$ is the mean thermal expansion coefficient of each phase at instantaneous temperature.

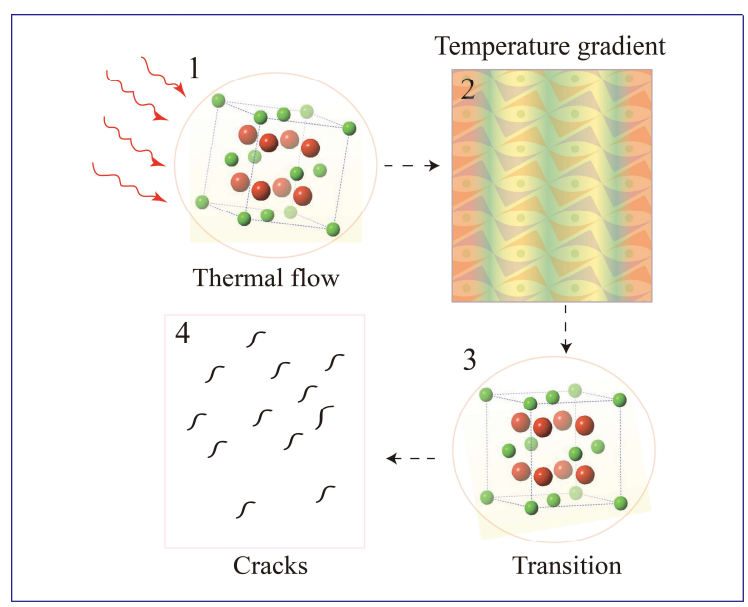

Fig.1. The essential conditions of thermal shock failure in transformational ceramic

\section{Experimental materials and techniques}

The compositions of raw materials were shown in Table I. The raw material powders were compounded with $10 \mathrm{vol} \%$ PVA aqueous suspension called semidry process and dried in furnace at $373 \mathrm{~K}$ for 1 day. Then the powders were milled $3-5 \mathrm{~h}$ and isostatic pressed $\left(\mathrm{d}_{50}\right.$ is $\left.1-5 \mu \mathrm{m}\right)$ at $80 \mathrm{MPa}$ to form the required samples by forming machine. The formed biscuits were sintered under free atmosphere with a heating rate of $3^{\circ} \mathrm{C} / \mathrm{min}$. Two-step sintering program was carried out. Densities were calculated by Archimedes method. The thermal expansion coefficients of specimens $(20 \mathrm{~mm} \times 6 \mathrm{~mm} \times$ $6 \mathrm{~mm}$ ) were measured per $100^{\circ} \mathrm{C}$ from $20^{\circ} \mathrm{C}$ to $1500^{\circ} \mathrm{C}$ by thermal dilatometer (DIL402C, NETZSCH) with a heating rate of $10^{\circ} \mathrm{C} / \mathrm{min}$ and a vacuum level of $10^{-2} \mathrm{Mbar}$. Phase characteristics were presented by X-ray diffraction (Bruker D8, Cu$\mathrm{Ka}$ ) from $20^{\circ} \mathrm{C}$ to $1500^{\circ} \mathrm{C}$ with a heating rate of $10^{\circ} \mathrm{C} / \mathrm{min}$ (parameters: electric voltage $=40 \mathrm{kV}$, electric current $=40 \mathrm{~mA}$, 
scan range $2 \theta=20-90^{\circ}$ ). The data was collected after holding for $10 \mathrm{~min}$ at $100^{\circ} \mathrm{C}$ intervals. The phase contents were calculated by the widely cited formula [8].

$V_{m}(\%)=\frac{I_{m}(111)+I_{m}(11 \overline{1})}{I_{m}(111)+I_{m}(11 \overline{1})+I_{t+c}(111)} \times 100 \%$

Table I. Materials compositions

\begin{tabular}{lllllll}
\hline & Sintering & \multicolumn{6}{c}{ Compositions (wt. \%) } \\
\cline { 3 - 7 } & & $\mathrm{A}$ & $\mathrm{B}$ & $\mathrm{C}$ & $\mathrm{D}$ & $\mathrm{E}$ \\
\hline $\mathrm{PSZ}-1$ & $1600^{\circ} \mathrm{C} \times 2 \mathrm{~h}+$ & 60 & 21 & 10 & 9 & others \\
& $1150^{\circ} \mathrm{C} \times 2 \mathrm{~h}$ & & & & & \\
$\mathrm{PSZ}-2$ & same & 65 & 18 & 10 & 7 & others \\
$\mathrm{PSZ}-3$ & same & 60 & 18 & 15 & 7 & others \\
\hline
\end{tabular}

*Note: Where $\mathrm{A}$ is $3 \mathrm{~mol} \mathrm{Y}_{2} \mathrm{O}_{3}-\mathrm{ZrO}_{2}$; $\mathrm{B}$ is $10 \mathrm{~mol} \mathrm{MgO}-\mathrm{ZrO}_{2}$; C is $10 \mathrm{~mol} \mathrm{CaO}-\mathrm{ZrO}_{2}$; D is $80 \mathrm{wt} \% \mathrm{Al}_{2} \mathrm{O}_{3}-\mathrm{ZrO}_{2}$.

The thermal shock tests were conducted by Water quenched - Residual strength method. No polished ceramic bodies $(20 \mathrm{~mm} \times 6 \mathrm{~mm} \times 6 \mathrm{~mm})$ were placed at $1000^{\circ} \mathrm{C}$ for $30 \mathrm{~min}$ and then quenched immediately in water (ambient temperature). The three-point bending strength of dried samples were measured by Electro-mechanical Universal Testing (CMT 6203, China) with setting the span of $40 \mathrm{~mm}$, loading speed of $0.5 \mathrm{~mm} / \mathrm{min}$. The mean value of residual strength was calculated from same batch of five samples under the same measurement condition. The microstructure and diffraction pattern were observed by transmission electron microscopy (TEM, Tecnai G220, FEI) after ionization thinning. The microcracks of specimens after thermal shock were observed by scanning electron microscope (Quanta 200, FEI).

\section{Results}

Residual strengths and phase characteristics

For mathematical expediency, only the volume fractions about $1 / 2,1 / 3$ and $1 / 4$ of $M$ phase in samples were selected. Figure 2(a) shows the retained strength ratios of specimens PSZ-1, PSZ-2 and PSZ-3 (relative densities $\geq 98 \%$ ) after quenched. From figure 2(a), it is evident that the strength of PSZ-3 reduces greatly after first shocked cycle. But the residual strengths of PSZ-1 and PSZ-2 are not obviously varied under the same thermal shock condition. Moreover, it is clear that the residual strength of PSZ-3 falls to $62 \%$ of initial value. However, only the strength of PSZ-3 did not continue declining after 5-6 times shocked. Figure 2(b) shows the microcracks along the large grain bound in PSZ-3 specimen after six thermal shock cycles observed by SEM.
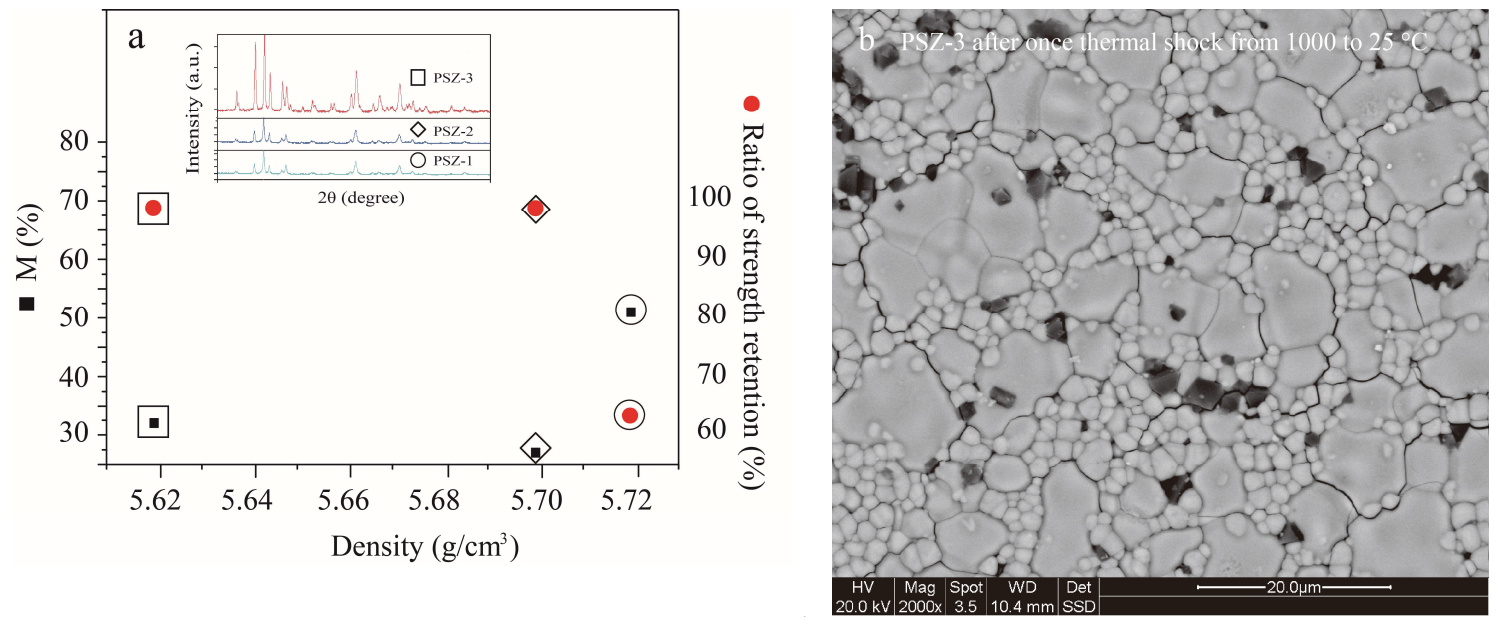

Fig.2. (a) The XRD patterns, retained strength ratios and densities of polymorph zirconia bodies after first shocked cycle, (b) Microcracks in PSZ-3 specimen after 6 shocked cycles observed by SEM

Thermal expansion behaviors and microstructure

To study the effect of temperature on transition, thermal expansion testing was carried out. From figure 3 , it is noted that the start-end temperatures of transition in PSZ-1, PSZ-2 and PSZ-3 specimens are different. But the temperature range of transition named as effective transition field $\Delta \mathrm{T}$ is similar each other. It means that the $\mathrm{M}$ content only affects the point of start and end transitional temperatures. Hence, the effective transition field is universal in other polymorph zirconia materials under a similar heating-up condition. 


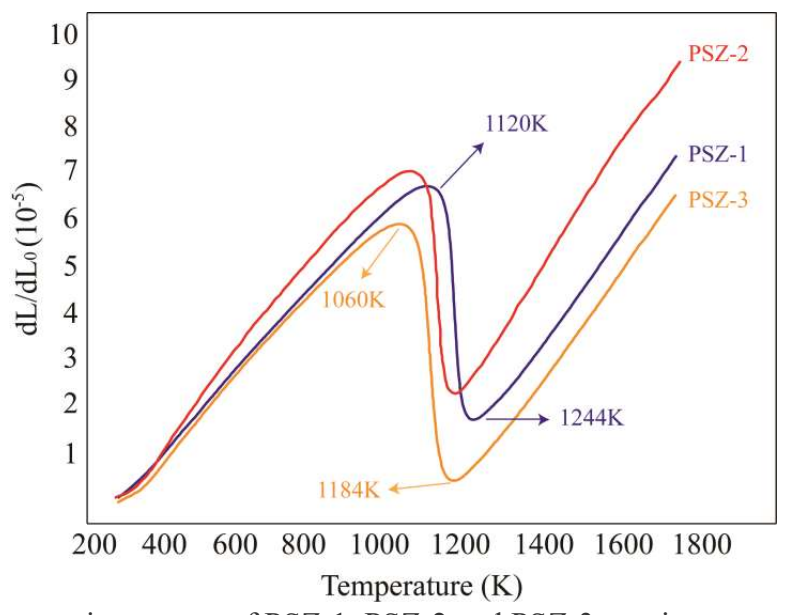

Fig.3. Thermal expansion curves of PSZ-1, PSZ-2 and PSZ-3 specimens among $25-1500^{\circ} \mathrm{C}$

To further investigate the microstructure, transmission electronic microscope (TEM) studies were carried out on PSZ-3 specimen. From figure 4, the convexity band edge around the block M phase and the concavity band edge between the lath-shaped $\mathrm{T}$ phases can be observed. These structures could make the cracks propagation route more sinuous due to the difference of properties such as brittleness, strength, shape etc, which also provide toughening effect during thermal shock.
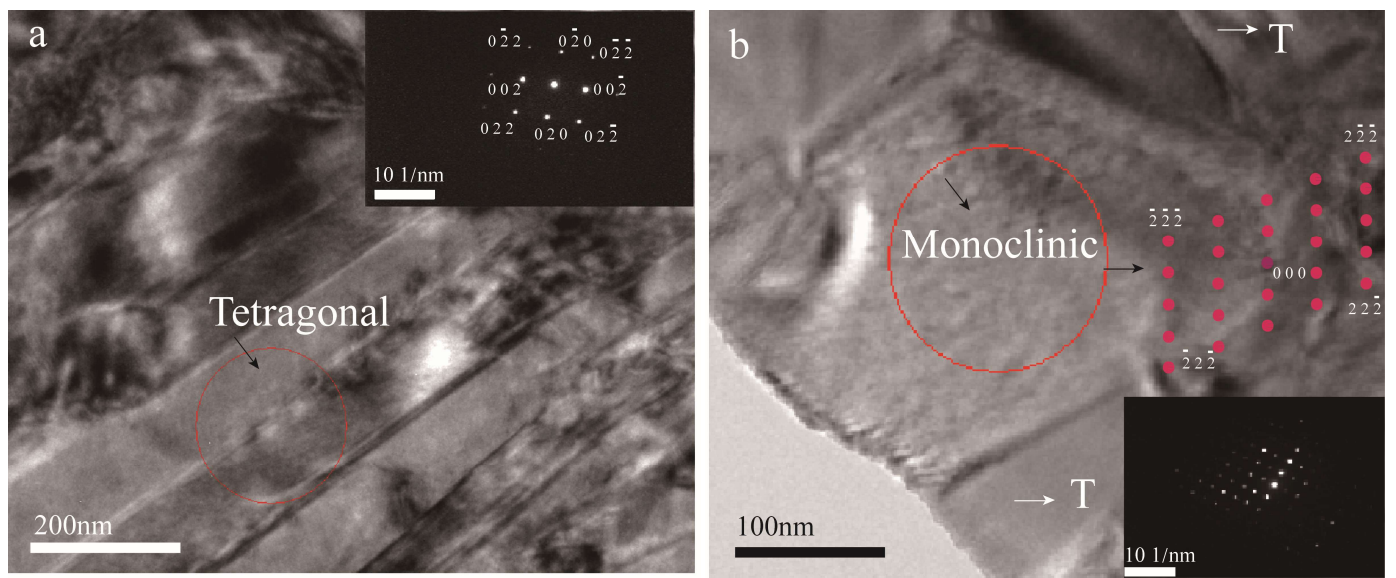

Fig.4. The diffraction patterns and microstructure images of PSZ-3 observed by TEM

\section{Discussion}

From Figure 2, it can be learned that the declined strength of $30 \%$ as criterion for $\Delta \mathrm{T}$ during thermal shock, does not spread to that of thermal shock durability. No more reduced but still higher strength is expected, though there are some microcracks. It is deduced that the transition induced crack self-restoration could play a role in avoiding cracks propagation during thermal shock. Cutler [9] presented the good toughness related with high M content. But Garvie [10] reported the toughening of ceramic could come from high density micro cracks which absorb the fracture energy. Actually, there are many discrepancies between the cracks occurred at different shocked cycles. Moreover, the transformation is not identical because of the difference of $\mathrm{M}$ phase content in samples, even though the features of cracks are same in first cycle. If a large numbers of cracks, the cracks tend to form long cracks during the next shocked cycle. The strength is commonly reduced. But the shorter cracks usually make a toughening called crack effect by Hasselman. The effect of crack size was studied by Gogotsi [6], but there was not headlined the role of healed cracks from transition which could play a key role in thermal shock durability.

If accelerating heat input like thermal shock, the transition would be layer-by-layer changed because of temperature gradients which differs from the case in Figure 3. Cracks would occur if the alternation of transition and expansion is no order. Because of the faster rate of transition than that of temperature and thermal stress variation [11], the negative volume change from transition can partially offset the thermal deformation and release the thermal stress-strain energy. But this volume change effect was not found in porosity PSZ ceramic [12]. Here we demonstrated that with the increasing of $\mathrm{M}$ phase and without density loss, the thermal shock durability was improved.

As seen from figure 2 and figure 3, the mean thermal expansion coefficient and strength are negatively related with initial $\mathrm{M}$ phase content, but the sensitivity of influence is not same. The foregoing results illustrate that keeping the 
volume stable is an effective way to improve the thermal shock durability. Therefore, based on the equations of (2), (3), and (4) mentioned hereinbefore, a suggested relationship of $|\mathrm{K}|$ (as normalized $\mathrm{K}$ ) and $\Delta \mathrm{V}$ corresponding to phase evolution is shown in figure 5. A mutation of thermal shock performance at transition temperature would occur owing to the discontinuous structure-dependent physical properties.
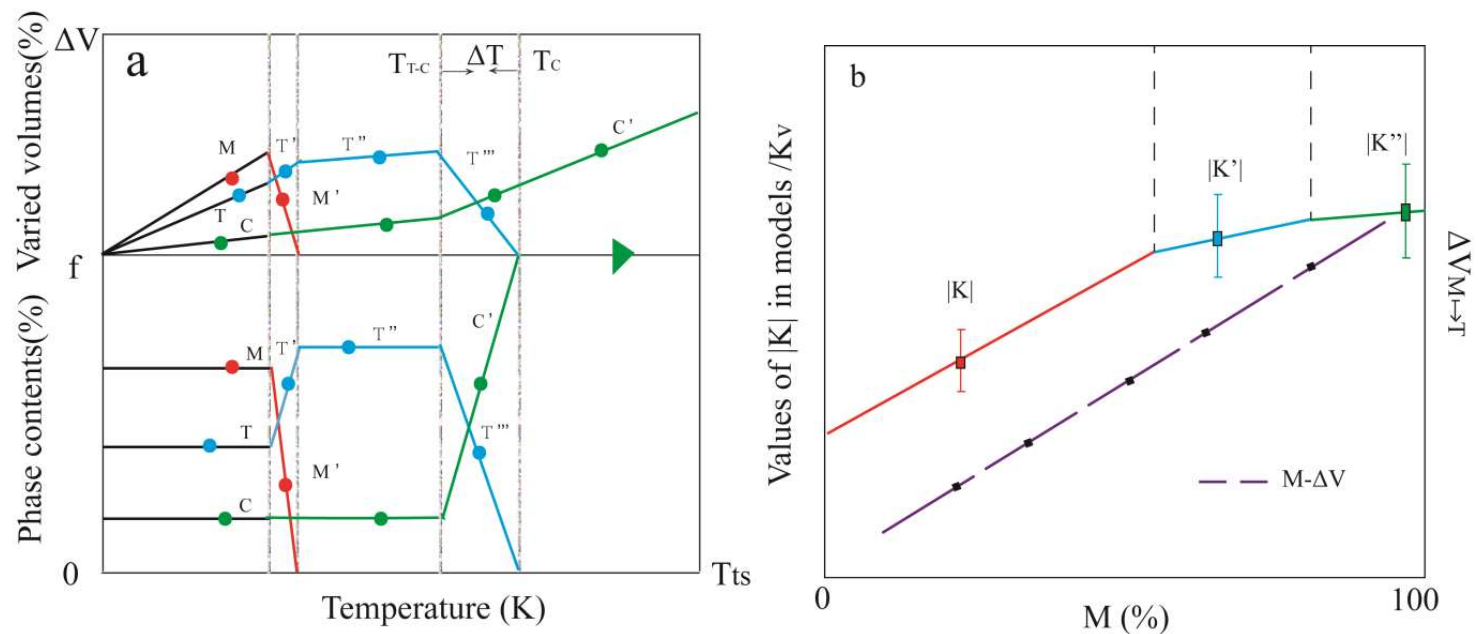

Fig.5. The relationship of $|\mathrm{K}|$ and $\Delta \mathrm{V}$ in polymorph zirconia, presuming the volume fraction of three phases is $\mathrm{M}>\mathrm{T}>\mathrm{C}$

As for polymorph zirconia material, with a considerable expansion allowance, the failure is logically impossible to occur at the temperature lower than $\mathrm{T}_{\mathrm{M}-\mathrm{T}}$ on basis of Griffith's theory. In this paper, the initial thermal environment temperature is indirectly elevated to the transition temperature because of the volumetric equilibrium effect. This could provide a repeatable reference to design special zirconia components.

\section{Conclusion}

As a more concise reference to design polymorph zirconia ceramics, the volume stability model based on phase characteristics is proposed. From experimental results, here it is found that the amplitude of transition was a factor to influence thermal shock durability. The cracks in first shocked cycle and phase transition induced clogging interacted with microstructures are play roles in improving thermal shock durability of polymorph zirconia ceramic. The K correlated with the initial phase proportion could provide a parallel governing principle to prepare polymorph zirconia ceramic used in special components. As a further studying, the stress distribution mechanism in polymorph zirconia will be investigated to explore the effect of transition on cracks behavior for stress relaxation.

\section{Acknowledgments}

Thanks are kindly expressed to Prof. Jianzhong Xiao for his supported to finish the experiments. The authors are grateful for the Analysis and Testing Center of Wuhan University of Technology for thermal expansion tests, as well as the Analysis and Testing Center of Huazhong University of Science and Technology for XRD and TEM tests.

\section{Data Accessibility}

All relevant data are within the paper and available online after being printed.

\section{Competing Interests}

We have no competing interests.

\section{Authors' Contributions}

Yonggang Hoo collected the data, participated in analysis and interpretation of data and the design of the study, drafted the manuscript; Wenzhong Lu participated in revising the manuscript; Yusheng Shi participated in data analysis, coordinated the study. All the authors edited the manuscript. Also, we thank the anonymous referees for their suggestions.

\section{Funding}

This work was partially supported by the National Key Foundation Research plan of China (61362) and Postdoctoral plan of Huazhong University of Science and Technology (2016-31). 


\section{References}

1. W.D. Kingery, 1955, Factors affecting thermal stress resistance of ceramic materials, Journal of the American Ceramic Society 38, 3-15. (doi:10.1111/j.1151-

2916.1955.tb14545.x)

2. D.P.H. Hasselman, 1969, Unified theory of thermal shock fracture initiation and crack propagation in brittle ceramics, Journal of the American Ceramic Society 52, 600-604. ( doi:10.1111/j.1151-

2916.1969.tb15848.x)

3. V.R. Salvini, V.C. Pandolfelli, R.C. Bradt, 2012, Extension of Hasselman's thermal shock theory for crack/microstructure interactions in refractories, Ceramics

International 38, 5369-5375.

(doi:10.1016/j.ceramint.2012.03.046)

4. W.G. Li, D.N. Fang, 2008, Effects of thermal environments on the thermal

shock resistance of ultra-high temperature ceramics, Modern Physics Letters B 22, 13751380. (doi:10.1142/S021798490801608X)
5. G.A. Gogotsi, Y.L. Groushevsky, K.K. Strelov, 1978, The significance of non-elastic deformation in the fracture of heterogeneous ceramic materials, Ceramurgia International 4, 113-118. (doi:10.1016/03905519(78)90095-9)

6. G.A. Gogotsi, 2009, Fracture behaviour of Mg-PSZ ceramics: Comparative estimates, Ceramics International 35, 2735-2740. (doi:10.1016/j.ceramint.2009.03.007) 7. D. Lewis, 1980 , Comparison of critical $\Delta \mathrm{T}_{\mathrm{C}}$ values in thermal shock with the R parameter, Journal of the American Ceramic Society 63, 713-714. (doi:10.1111/j.11512916.1980.tb09868.x)

8. R.C. Garvie, P.S. Nicholson, 1972, Phase analysis in zirconia systems, Journal of the American Ceramic Society 55, 303-305. (doi:10.1111/j.1151-2916.1972.tb11290.x)
9. R.A. Cutler, J.R. Reynolds, A. Jones, 1992, Sintering and characterization of polycrystalline monoclinic, tetragonal, and cubic zirconia, Journal of the American Ceramic Society 75, 2173-2183. (doi:10.1111/j.1151-2916.1992.tb04480.x) 10. R.C. Garvie, P.S. Nicholson, 1972, Structure and thermomechanical properties of partially stabilized zirconia in the $\mathrm{CaO}-\mathrm{ZrO}_{2}$ system, Journal of the American Ceramic Society 55, 152-157. (doi:10.1111/j.11512916.1972.tb11241.x)

11. H.S. Maiti, K.V.G.K. Gokhale, E.C.

Subbarao, 1972, Kinetics and burst phenomenon in $\mathrm{ZrO} 2$ transformation, Journal of the American Ceramic Society 55, 317-322. (doi:10.1111/j.1151-2916.1972.tb11294.x)

12. W.C.J. Wei, Y.P. Lin, 2000, Mechanical and thermal shock properties of size graded MgO-PSZ refractory, Journal of the European Ceramic Society 20, 1159-1167. (doi:10.1016/S0955-2219(99)00243-5) 